\title{
The Changing Ecology of Infectious Diseases in Human
}

\author{
Fatik Baran Mandal
}

Department of Zoology, Bankura Christian College, Bankura, PIN: 722101, West Bengal, India

\begin{abstract}
A number of pathogens are continuing to be accounted for a major part of our ill-heath, unwanted death and reasonably is a matter of serious concern. Anthropogenic disturbances of natural ecosystems like forest clearance, contamination of soil, water and food provide the ideal condition for the outbreak of parasitic diseases. Human population growth and malnutrition are also associated with the parasitic diseases. Interdisciplinary research involving foresters, ecologists, wildlife experts, and parasitologists is required for better understanding the current pattern of spread of human parasitic diseases along with their virulence. Agricultural irrigation, dam construction, and land degradation are related to spread of human parasitic diseases. Involvement of local communities in prevention of disease can increase the efficacy of disease management. The present paper highlights the consequences of anthropogenic ecological disturbances and other factors in spread of human parasitic diseases in light of recent findings.
\end{abstract}

Keywords Infectious Diseasess, Vector-Borne, Malnutrition, Land Degradation, Food Contamination

\section{Introduction}

Human population is limited partially or completely by diseases .Infectious diseases cause approximately $37 \%$ of all human deaths worldwide[1]. Infants and children death of 4 million per year from diarrhoea alone is largely due to contaminated water and food[2]. Disease prevalence is influenced by infectious organisms, pollutants, and malnutrition[3]. Complex of factors and their interactions are associated with disease prevalence /or outbreak. As countries develop, there occurs a transition from high-birth, high death rate societies to low birth, low-death rate state societies. This causes population expansion. Coupled with economic growth, this creates new demands for energy, transport, food and natural resource products. All of these functions serve as driving forces of environmental change[4]. Human population growth demands expansion of agricultural production, water management, irrigation schemes, hydroelectric dam construction, deforestation, urbanization, and unsustainable exploitation of natural resources creating new pressures on ecosystems that in turn have profound impacts on vector habitats, carrying capacity of environment for vector populations, and infectious disease transmission[5]. Introduction of exotic species also spreads infectious disease. For example, the introduction of Plasmodium relictum in the Hawaiian Islands resulted in a catastrophic decline in endemic avifauna[6].

\section{Present Trends of Infectious Diseases}

* Corresponding author:

fatikspeaking@yahoo.co.in (Fatik Baran Mandal)

Published online at http://journal.sapub.org/env

Copyright (C 2011 Scientific \& Academic Publishing. All Rights Reserved
Over $60 \%$ of human pathogens infect multiple host species. More than 100 parasite species from wild primates are reported in humans, nearly all of which could infect hosts from multiple orders or families. Distribution and population biology of multi-host pathogens is becoming increasingly important for human health[7].Current episode of global infectious disease emergence is due to interaction among genetic, biological, social, economic, political, and environmental factors. Causal factors of infectious disease emergence include land use change, human movement, encroachment and wildlife translocation[see8]. Density- dependent thresholds of population for disease emergence explains the abrupt transitions of urban disease between non-persistence to endemic , and endemic to epidemic as population of susceptible humans, hosts and vectors attain critical densities. Many infections endemic on continents is not established on islands despite their occasional introduction and occurrence of local outbreaks. Pathogen reproductive rate increases with the square of vectors population density at least theoretically. Increased densities of humans, reservoir hosts and vectors increase the number of pathogen genomes. In artificial environment, a diminished capacity of ecosystem regulates vector abundance naturally. Density dependent regulation is also partly evident in Aedes aegypti based on their feeding success[9]. Density independent factors such as seasonality and climate variability are significant in regulating vector populations, in addition to temperature which affect dengue transmission rates by altering extrinsic incubation period in mosquitoes[10]. Persistence of a vector species within a particular ecosystem is often a balance between extinction and reorganization of population between heterogeneous patches of habitat[11]. Discontinuous vector population and efficiency of population dispersal result in genetically differentiated populations within the same eco- 
system of high degree of genetic variability and selective pressure on these populations result in possible emergence, spread and persistence of insecticide resistant genes ,or vector behavioral changes that facilitate transmission[12].

Probability of production of virulent variants increases with host population size, and crowding and co-mingling of different host species[13]. Parasite-host relation constitute a co-adaptive, evolutionary dance along the pathogenicity threshold which is likely to be crossed due to anthropogenic disturbances[14]. Deforestation, indiscriminate use of pesticides and other pollutants often result in loss of predators. Carnivorous mammals are the first species to disappear following forest fragmentation. Their local extinction represents the loss of "top down" natural control in ecological communities, which result in abundance, even hyper abundance[15] of species like rodents and biting insects. An extension of the ecological release concept explains the invasive species phenomenon in which super-successful introduced (alien) species escape from their natural complement of parasites[16], predators and competitors. This may explain largely the success of invasive species, Rattus and Aedes which are hosts and vectors of most problematic urban zoonotic diseases. Reduction in species diversity contribute to ecological release in remaining species, whose predators, competitors, and parasites are reduced in numbers, or eliminated .Some of these may already serving as zoonotic reservoirs of vectors. If so, ecological release may result in their proliferation. This explains emergence of many zoonotic diseases in areas where settlement and agricultural expansion encroaches tropical forests. Heterogeneity dramatically influences the dynamics of natural systems. Understanding the sources of variation underlying disease, or vector dynamics facilitates targeted control. For example, larviciding campaigns focusing on the most productive larvae developmental sites may lead to dramatic and cost- effective disease reduction[17]. Perhaps, the process influencing transmission of zoonotic pathogens can be due to expansion of habitat of a host, a pathogen, or both, expansion of human habitat, or change in habitat occupied by both humans and natural host.

\subsection{Mechanisms of Disease Emergence}

Three ecological trends viz., vector and reservoir domestication (or peri- domestication), invasion of domestic habitat by opportunistic wildlife, and invasion of natural habitat by feral species are associated with disease emergence. Convergence of human and animal hosts and reservoir and vector species within ecosystems, and movement, shifting and mixing across the ecosystem continuum affects hostpathogen dynamics in a manner that facilitates disease emergence. Pathogens get increased opportunities for host switching .Transmission is amplified, and opportunity for rapid evolution increases with multiple, interacting transmission cycles. Pathogen's infectivity exceeds the threshold which is required to produce an epidemic, or an endemic disease, owing to unprecedented vector population densities, reservoir and susceptible human populations. Pathogens evolve increased pathogencity, infectivity and ability to avoid immune system detection, due to increased opportunities for interaction of endemic infection cycles and pathogen strains, and greater density and genetic variability of pathogen populations. Changes in land cover and land use including forest cover along with urbanization and agricultural intensification are major factors for infectious diseases coinciding with accelerating rates of tropical deforestation in the last several decades. Today both deforestation and emerging infectious diseases remain largely associated with tropical regions but have impacts that extend globally. Both are similarly intertwined with issues of economic development, land use and governance and require cross-sectoral solutions.

\subsection{Human Population Growth, Malnutrition and Diseases}

The world's population is predicted to reach 12 billion in the next 50 years. The US population alone will double to 540 million during the next 70 years[18]. Densely crowded urban environments especially those without adequate sanitation are sources of disease epidemics. Dengue trans- mitted by Ae. aegypti is expanding rapidly in crowded tropical cities[19] and has increased dramatically since 1980, with $30-60$ million infections now occurring each year[20,21]. In 1950, 500 million people were considered maln- ourished. Today over 3 billion people suffer from maln- utrition[22], the largest number and the highest rate in history. Each year, between 6 and 14 million people die from malnutrition[23]. Malnutrition problems are also increasing in the United States. Malnutrition complicated by parasitic infections is frequently found in poverty-stricken areas with inadequate sanitation. Malnourished individuals especially children are seriously affected by parasitic infections because infections reduce nutrient availability. Presence of intestinal parasites frequently diminishes appetite and food intake. Their presence also increases the loss of nutrients by causing diarrhoea and dysentery. Hookworms suck as much as $30 \mathrm{ml}$ blood from an infected person each day, gradually weaken individuals, and lower their resistance to other diseases[24]. Because an estimated $5-20 \%$ of an individual's daily food intake is used to offset the effects of parasitic illnesses, the overall nutritional status of a parasite-infected person is greatly diminished over time[25].

\subsection{Water-borne Diseases}

Water-borne pathogens include enteric viruses, bacteria Campylobacter spp. and Vibrio cholerae. Other water-borne EIDs (Emerging Infectious Diseases) include protozoan of the genera Cryptosporidium and Giardia. Some disease outbreaks in the United States are due to the spread Cryptosporidium parvum and Giardia lamblia. Protozoans like Entamoeba, Sarcocystis, Toxoplasma, Neospora, Cyclospora, Acanthamoeba, Naegleria, Balamuthia and Microsporidia use water route for transmission.Among micro- 
sporidoian, Enterocytozoon, Encephalitozoon, Pleistophora, Trachipleistophora, vittaforma, Brachiola and Nosema are reported[26]. During the past 30-40 years, infection rate in the United States caused by these waterborne organisms has increased[27]. Schistosomias, associated with contaminated fresh water, is expanding worldwide and currently causes an estimated 1 million deaths annually due to an increase in suitable habitats for snail intermediate-host population resulting from construction of dams and irrigation channels[28]. Environmental changes including more polluted water foster the high incidence and increase of malaria.

\subsection{Land Degradation and Disease Prevalence}

Soil is easily contaminated by a wide array of pathogens. Humans acquire pathogens directly from soil .As people invade natural ecosystems and land is cleared of trees, soil is exposed and chances of human infection increase by helminthes, such as hookworms, and microbes[2]. Such increases were observed in 1984 in Nepal, a mountainous country that is experiencing serious soil erosion and severe disease problems: $87 \%$ of the population was infected with helminthes[29]. Children suffer greater morbidity from helminth infections than adults, because children need more protein than adults per kilogram of body weight. Under severe parasitic infections, they can not utilize protein efficiently enough to remain healthy. Many helminth species that infect humans are found in soil contaminated by human faeces, thereby exacerbating the cycle of exposure. Worldwide, approximately 2 billion people are estimated to be infected with one or more helminth species, either by direct penetration, or by consumption of contaminated food or water[30]. The most prevalent helminthes are hookworms (Necator americanus and Ancylostoma duodenale), Strongyloides (Strongyloides stercoralis), and Ascarids (Ascaris lumbricoides). In locations in which sanitation is poor and people are overcrowded, as in parts of urban Africa, up to $90 \%$ of the population may be infected with one or more helminth species[31]. Transmission of Taenia and Trichiurus also occurs through contaminated soil.

\subsection{Infectious Disease and Forests}

Land use change and expansion of human populations into forest areas results in exposure of immunologically naive human and domestic animal populations to pathogens occurring naturally in wildlife. Forest clearance and alteration causes an increase in abundance, or dispersal of pathogens by influencing host and vector abundance and distribution which increase infection rate, increase the frequency of their contact with humans. It allows the pathogen to persist indefinitely and the disease to become endemic. In all, about three-fourths of recognized EIDs either once were, or currently are zoonotic, i.e. transmitted between animals and humans[32]. Pathogens whose current emergence patterns show a direct association with forests represent about $15 \%$ of the approximately 250 EIDs[33]. Some EIDs not currently associated with forests originated from a sylvatic cycle, but have since "escaped" and are now solely maintained by human-human transmission, or a human-vector-human cycle independent of forests. The HIV and dengue broke free from their primate transmission cycles in African forests, and eventually spread globally two decades ago in case of HIV, and several centuries ago for dengue. For EIDs currently associated with forests, many are transmitted among non-human primate hosts, or insect vectors, and involve a variety of potential intermediate hosts including domestic animals. Although relatively few plant parasites or pathogens are known to infect animals including humans, the impact of emerging plant diseases on plant populations is also an increasing concern.

AIDS originated in tropical forest and expanded throughout a region that was undergoing changes and lacked public health infrastructure. Increased malaria incidence in some areas of Africa, South America and Southeast Asia is linked to deforestation[34]. A form of malaria previously found in non-human primates has recently been found in humans in Southeast Asia[35]. Hunting, butchering or illegal procurement of these animals increases the risk of disease emergence[36]. Deforestation in Africa has exposed land to sunlight and promotes the development of temporary pools of water, thus favoring the breeding of human-biting, malaria-transmitting mosquitoes, Anopheles gambiae[37].

\subsection{Food Contamination and Disease}

Worldwide, reported cases of food-borne diseases are as high as 240 million per year[38]. In the United States, approximately 6.5 million food- borne disease cases occur each year, causing approximately 9000 deaths[39].Poultry, hogs, cattle, and other animals are easily contaminated with Salmonella enteritidis, especially when they are crowded together in husbandry facilities with inadequate waste disposal systems [19]. Further microbial contamination can be caused by unsanitary conditions during slaughtering, processing, and handling. In the United States, hen eggs are the main source of $S$. enteritidi which can cause severe gastrointestinal illnesses and sometimes death in humans, especially among children and the infirm[40].

\subsection{Vector-borne Disease Management}

Importance of ecological context in management of vector-borne diseases was likely realized immediately following the discovery of arthropods as vectors of disease in 1877 . Klinger[41] pointed to the "need to have a thorough knowledge of breeding places and habits, and to apply the most suitable methods to the situation." In the late 19th and early to mid 20th centuries, early vector-borne disease research concentrated on explaining the natural history, taxonomy, biology and distribution of organisms[42]. Ecology based vector control methods received a boost beginning in the 1960s, when the use of persistent chemical pesticides like DDT came into question due to their negative impacts. Using biological and ecological approaches thus began to be advocated[43]. A phase shift occurred during the last few 
decades in which most regional ecosystems in the world transformed from largely natural landscape and non- intensively cultivated cropland to primarily human dominated landscape[44]. That vector-borne disease management evolved towards a more integrated, holistic, ecology based science is reflected in the emergence of "integrated control" in the 1960s, followed by "integrated pest management" in the 1970s, and "integrated vector control" and "communitybased participatory" approaches emerging in the 1980s[45]. At least 25 diseases are associated with vector. Ecological changes, human demographic changes and behaviors, technology and industry, travel and commerce; microbial adaptation and change, breakdown in public health measures are responsible for emergence of infections diseases[see 46].

Vector biology is the study of arthropod vectors and their role in pathogen transmission which encompasses entomology, ecology, microbiology and epidemiology and merges approaches ranging from landscape ecology to functional genomics[47]. Over the past 2 decades, scientists have concentrated their efforts on genetic strategies to suppress vectors population or render them incapable of transmitting pathogens[48]. History shows that properly done vector control can effectively reduce disease transmission[49]. However, current control strategies are ineffective or insufficient to control vector borne diseases (re) emergence[50], and breakthroughs in genomics and molecular entomology have yet to result in improved public health outcomes[51]. But knowledge of Aedes aegypti larval developmental sites and indoor resting behaviour has led to the development of container covers and insecticide treated window curtains for low-tech and low-cost prevention of dengue[52]. Diversifying the vector biology research agenda to include ecology, behaviour and population biology of vectors is necessary to ensure the success of genetic control methods [53] and to provide alternative disease control tools. The "genomic era" for vector biology was heralded by publication of the genome sequence of the African malaria vector, Anopheles gambiae[54]. Genomic data of invertebrate vectors of human pathogen have been made easily available through the web-based bioinformatics resource centre, vectorBase[55]. Such breakthroughs have revived interest in developing strategies to replace or eliminate natural vectors[48], identifying new molecular targets for insecticide design and developing olfaction driven vector control strategies[56].

\section{Conclusions}

Crowded urban areas are ideal for resurgence and rapid spread of old diseases as well as for development and spread of new diseases. Widespread malnutrition enhances susceptibility of humans to infectious pathogens and other diseases. Rapid changes associated with globalization, especially the rapidly increasing ease of mixing people, domestic animals, wildlife and plants, along with their parasites and pathogens now occurs at an unprecedented frequency. Research on infectious diseases involving the ecological epidemiology of zoonotic and vector-borne diseases associated with forests needs to be integrated with forest resource management and planning. Greater emphasis is needed on integrating research and practice. Interdis- ciplinary research among foresters, forest ecologists, and wildlife and human infectious disease experts for understanding the role and impact of forests and forest land use may help in management of human parasitic diseases. Translating knowledge into effective disease control strategies requires collaboration between scientists and health professionals, among the different public and private sectors. For example, development activities such as agricultural irrigation, dam construction and forest clearance can greatly affect vector borne disease transmission. Cooperation between health and agricultural sectors in rice- growing regions of Asia, for example, has lead to promotion of intermittent irrigation and coordinated insecticide application as avenues to improve control of malaria[57]. Engaging local communities to understand and plan how to improve health situation may lead to greater and more sustainable impact on disease transmission .

\section{REFERENCES}

[1] Real, L.A., 1996, Sustainability and the ecology of infectious diseases. BioScience, 46, 88-97

[2] WHO., Our planet, our health: Report of the WHO commission on health and environment, Geneva, 1992

[3] R. Dubos., Man Adapting, New Haven (CT): Yale University Press. 1965

[4] A. J. McMichael., Human frontiers, Environments and Diseases: Past pattern, uncertain futures, Cambridge, U. K.: Cambridge University Press, 2001

[5] Molyneux, D.H., 2003, Common themes in changing vector-borne disease scenarios. Trans. Roy. Soc. Trop. Med. Parasitol., 97,129-132

[6] Atkinson. C.T., Dusek. R.J., Woods. K.L., Iko, W.M., 2000, Pathogenecity of avian malaria in experimentally -infected Hawaii Amakihi., J. Wildlife Dis., 36,197-204

[7] Pedersen AB, Altizer S, Poss M, Cunningham AA, Nunn CL. Patterns of host specificity and transmission among parasites of wild primates. International Journal for Parasitology, 2005; 35: 647-657.( written as C.L. ,2005, Nunn)

[8] Wilcox, B.A. and Gubler, D.J., 2005, Disease ecology and the global emergence of zoonotic pathogens., Environmental Health and Preventive Medicines ,10, 263-272

[9] Schofield, C.J., 1971, Vector population responses to control intervention. Ann. Soc. Belg. Med. Trop., 71 Suppl 1: 201-17

[10] Jetten, J.H., Flocks, D.A. 1997, Potential changes in the distribution of dengue transmission under climate warming. Am.J. Trop. Med.Hyg. , 57: 285-297

[11] Farina, A., Principles and methods in landscape ecology: towards a science of landscape. Dordrecht: Springer. 2006 
[12] Ocampo CB, Wesson DM. Population dynamics of Aedes aegypti from a dengue hyper endemic urban setting in Colombia. Am. J. Trop. Med. Hyg. 2004;71: 506-513

[13] Schrag, S.S., Wiener, P., 1995, emerging infections disease: what are the relative roles of ecology and evolution? Trends Ecol. Evol., 10, 319-324

[14] Horwitz, P., Wilcox, B.A., 2005, Parasites, ecosystems and sustainability; some notes on nested interdependencies. Int. J. Parasitol., 35, 725-732

[15] Terborgh, J., Lopez, L. et.al.2001, Ecological meltdown in predator-free forest fragments. Science, 294, 1923-1926

[16] Prenter J, Macneil C, Dick JTA, Dunn A M. Roles of parasites in animal invasions. Trends.Ecol.Evol. 2004; 19: $385-390$

[17] Gu, W., Utzinger, J. and Novak, R.J., 2008, Habitat- based larval interventions: a new perspective for malaria control. American journal of Tropical Medicine and Hygiene , 78: 2-6

[18] USBC (US Bureau of the Census). Statistical Abstract of the United States, 1987. 107th ed. Washington (DC): US Government Printing Office

[19] Lederberg, J., Shope, R.E., Oaks, S.C. Emerging Infections: Microbial Threats to Health in the United States. Washington (DC): National Academy Press, 1992

[20] Monath, T.Pa., 1994, The risk to developed and developing countries. Proceedings of the National Academy of Sciences of the United States of America, 91, 2395-2400

[21] Monath, T.Pb, 1994, Yellow fever and dengue - the interactions of virus, vector and host in the re-emergence of epidemic disease. Seminars in Virology, 5(2), 133-145

[22] WHO. World food summit: Micronutrient malnutrition -- half of the world's population affected. Geneva: World Health Organization. Press Release No. 78. 1996

[23] Murray, C.J. L., Lopez, A.D. The Global Burden of Disease. Geneva: World Health Organization, 1996

[24] Hotez, P.J., Pritchard, D.T., 1995, Hookworm infection. Scientific American. ,272 (6), 68-75

[25] Pimentel, D., Pimentel, M., Food, Energy and Society. Niwot (CO): University Press of Colorado, 1996

[26] Franzen, C. and Muller, A., 2001, Microsporidiosis: human diseases and diagnosis. Microbes and infection., 3,389-400

[27] Guerrant R.L., 1997, Cryptosporidiosis: An emerging, highly infectious threat. Emerging Infectious Diseases, 3, 1-6

[28] Shiklomanov, I.A. World fresh water resources. Pages 13-24 in Gleick P, ed. Water in Crisis: A Guide to the World's Fresh Water Resources. Oxford (UK): Oxford University Press. 1993

[29] Metz, J.J., 1991, A reassessment of the causes and severity of Nepal's environmental crisis. World Development, 19, $805-820$

[30] Hotez, P.J., Hawdon, J.M., Cappello, M., Jones, B.F., Ghosh, K., Volvoritz, F., Xiao, S., 1996, Molecular approaches to vaccinating against hookworm disease. Pediatric Research,
$40,515-521$

[31] Stephenson, L.S., 1994, Helminth parasites: A major factor in malnutrition. World Health Forum, 15, 169-172

[32] Taylor, L.H., Latham, S.M. and Woolhouse,M.E. 2001,Risk factors for human disease emergence. Philosophical Transactions of the Royal Society of London, Series B, Biological Science, 356(1411), 983-989

[33] Despommier D, Ellis B.R and Wilcox BA. The role of ecotones in emerging infectious diseases. EcoHealth. 2006,3(4), 281-289

[34] Vittor, A.Y., Gilman, R.H., Tielsch, J., Glass, G., Shields, T., Lozano, W.S., Pinedo-Cancino, V., and Patz, J.A.,2006, The effect of deforestation on the human-biting rate of Anopheles darlingi, the primary vector of falciparum malaria in the Peruvian Amazon. American Journal of Tropical Medicine and Hygiene, 74(1), 3-11

[35] Singh B., Kim Sung L, Matusop A, Radhakrishnan A, Shamsul SS, Cox-Singh J, Thomas A and Conway DJ. A large focus of naturally acquired Plasmodium knowlesi infections in human beings. Lancet,2004, 363(9414), $1017-1024$

[36] Wolfe, N.D., Daszak, P., Kilpatrick, A.M. and Burke, D.S.,2005, Bushmeat hunting, deforestation, and prediction of zoonoses emergence. Emerging Infectious Diseases ,11(12), 1822-1827

[37] Coluzzi M. Malaria and the afro tropical ecosystems: Impact of man-made environmental changes. Parasitologia ,1994,36: 223-227

[38] WHO. Public Health Impact of Pesticides in Agriculture. Geneva, 1990

[39] Todd, E.C.D.,1996, Worldwide surveillance of food-borne disease. Journal of Food Protection ,1, 82-92

[40] Altekruse, S.F., Swerdlow, D.L.,1996, The changing epidemiology of food borne diseases. The American Journal of the Medical Sciences , 311, 23-29

[41] Klinger IJ. The epidemiology and control of malaria in Palestine Chicago: University of Chicago Press. 1930

[42] Schliessmann DJ, Calheiros LB. A review of the status of yellow fever and Aedes aegypti eradication programs in the Americas. Mosq. News., 1974; 34: 1-9

[43] Carson R. Silent Spring .New York: Fawcett Crest. 1964

[44] Turner BL, Cark WC. et al., The earth as transformed by human action. Global and regional changes in the biosphere over the last 300 years. Cambridge: Cambridge University Press, 1993

[45] Kogan M. Integrated pest management: historical perspectives and contemporary development. Annu. Rev. Entomol. $1998 ; 43,243-70$

[46] Ellis, B.R., Wilcox, B.A. 2009, the ecological dimensions of vector-borne disease research and control. Cad. Saude publica, Rio de Janeiro, 25 sup 1, 5155-5167

[47] Lambrechets, L., Knox, T.B., Wong, J., Liebman, K.A., Albright, R.G. and Stoddard, S.T., 2009, shifting priorities in vector biology to improve control of vector-borne disease. Tropical medicine and International Health, 14 (12), 1-10 
[48] Aultman KS, Beaty BJ and Walker ED. Genetically manipulated vectors of human disease: a practically overview. Trends in Parasitology 2001;17: 507-509

[49] Townson, H., Nathan, M.B., Zaim, M. et al., 2005, exploiting the potential of vector control for disease prevention. Bulletin of the world Health Organization , 83, 942-947

[50] Gubler, D.J., 1998, Resurgent vector-borne diseases as a global health problem. Emerging Infections Diseases, 4, $442-450$

[51] Fish D. Why we do not understand the ecological connections between the environment and human health. The case for vector borne disease. The National Academics Press. Washington, D.C. 2008

[52] Kroeger, A., Lenhart, A. and Ochoa, M., 2006, Effective control or dengue vectors with curtains and water container covers treated with insecticide in Mexico and Venezuela: cluster randomized trials. British Medical Journal, 332,
$1247-1252$

[53] Scott, T.W., Takken, W., Knols, B.G. and Boete, C., 2002, the ecology of genetically modified mosquitoes. Science, 298, 117-119.

[54] Holt RA. Subramanian GM, Halpern A et al, The genome sequence of the malaria mosquito Anopheles gambiae. Science 2002; 298: 129-149

[55] Lawson, D. Arensburger, P. et al., 2009, VectorBase: a data resource for invertebrate vector genomics. Nuclei Acids Research, 37, D583-D587

[56] Justice, R.W., Biessmann, H., Walter, M.F., Dimitratos, S.D. and Woods, D.F., 2003, Genomics spawns novel approaches to mosquito control. BioEssays ,25, 1011-1020

[57] WHO. Global strategies framework for integrated vector management. In: World Health Organization document WHO/CDS/CPE/PVC/2004. 10. World Health Organization, Geneva. 2004 